\title{
Vertical transport of pollutants by shallow cumuli from large eddy simulations
}

\author{
G. Chen ${ }^{1}$, H. Xue ${ }^{1}$, G. Feingold ${ }^{2}$, and X. Zhou ${ }^{1,3}$ \\ ${ }^{1}$ Department of Atmospheric and Oceanic Sciences, School of Physics, Peking University, Beijing, 100871, China \\ ${ }^{2}$ NOAA Earth System Research Laboratory, Boulder, CO 80305, USA \\ ${ }^{3}$ Chinese Academy of Meteorological Sciences, Beijing, 100081, China
}

Correspondence to: H. Xue (hxue@pku.edu.cn)

Received: 30 March 2012 - Published in Atmos. Chem. Phys. Discuss.: 3 May 2012

Revised: 19 October 2012 - Accepted: 5 November 2012 - Published: 3 December 2012

\begin{abstract}
This study investigates the vertical transport of a passive tracer in a shallow cumulus boundary layer using large eddy simulations. The tracer source is at the surface in one case, and in the inversion layer in the other case. Results show that shallow cumulus clouds can significantly enhance vertical transport of the tracer in both cases. In the case with surface-borne pollutants, cloudy regions are responsible for the upward transport, due to the intense updrafts in cumulus clouds. In the case where pollutants are aloft, cloud-free regions are responsible for the downward transport, but the downward transport mainly occurs in thin regions around cloud edges. This is consistent with previous aircraft measurements of downdrafts around cumulus clouds and indicates that the downward transport is also cloud-induced. $\mathrm{Cu}$ mulus convection is therefore able to both vent pollutants upward from the surface and fumigate pollutants in the inversion layer downward into the lower boundary layer.
\end{abstract}

\section{Introduction}

Apart from affecting the vertical structure of tropospheric radiative heat flux divergence, and modulating hydrologic cycle, convective clouds can also enhance the vertical mixing of gaseous matter and aerosol. Warm phase shallow convection can enhance vertical mixing in the boundary layer, but can hardly transport boundary layer air above the capping inversion (Cotton et al., 1995), while deep convection, usually associated with mixed phase clouds, can transport a large amount of reactive species to a high level rapidly before they are oxidized by photochemical reactions. According to the estimation of Cotton et al. (1995), cloud venting contributes an annual flux of $4.95 \times 10^{19} \mathrm{~kg}$ of boundary layer air into the cloud layer, which represents a venting of the entire boundary layer about 90 times a year.

Shallow cumulus covers about $12 \%$ over the ocean and $5 \%$ over the land (Warren et al., 1986, 1988), and has been shown to have a great effect on dispersing local pollutants based on both observational and modeling studies. A field experiment by Ching and Alkezeweeny (1986) showed that mixed layer pollutants are vented into the overlying cloud layer by active cumulus clouds, and that such active clouds may force cloud layer air downward into the mixed layer. Niewiadomski (1986) made a remarkable simulation on convective and turbulent transport of a passive pollutant using a 3 -D cloud model. It was shown that non-precipitating cumuli result in a great horizontal variability of the pollutant concentration and are quite effective in venting the polluted boundary layer, even though these cumuli are relatively sparse and weak. According to the estimation of Thompson et al. (1994), shallow cumulus and synoptic-scale weather systems together make a comparable venting flux of $\mathrm{CO}$ with deep convections, but the relative fluxes due to shallow convection and synoptic-scale weather systems are poorly known. Shallow convection must be taken into account in pollutant transport in the lower troposphere where most emissions take place. For example, in the wet season over a tropical rain forest, venting by shallow cumuli is proved to be the main process that modifies the redistribution of tracer species (Edy et al., 1996).

Transport of pollutants by cumulus clouds is not only a dynamical process, but also related to the chemical 
characteristics of the pollutants and their chemical reactions. Simulations by Flossmann and Wobrock (1996) showed that medium-sized precipitating cumulus clouds can scavenge a significant amount of soluble species and also release some species back into the air when the clouds evaporated, which suggested that clouds represent an efficient element in the environmental pollution chain (Flossmann, 1998). Vilà-Guerau de Arellano et al. (2005) pointed out that clouds can limit the reactions between pollutants by transporting reactants to different places. They also concluded that the photolysis rates perturbed by scattered radiation from cloud drops substantially affect pollutant mixing ratios locally, but have little effect on mixing ratios averaged over space and time.

In recent years, as the computational capabilities are greatly improved, modeling studies lead the way toward understanding cumulus processes, while observational studies are intended to validate model-based findings. Simulations by Zhao and Austin (2005a, b) revealed the toroidal circulation in shallow cumulus clouds. They argued that on average cumulus convection occurs in a region with timeintegrated volume roughly 2 to 3 times that of the liquidwater-containing volume. More recent studies proposed a refined view of vertical mass transport by cumulus that downdrafts outside clouds are confined in thin shell regions around cloud edges, and that the subsiding shell is attributed to evaporative cooling (Heus and Jonker, 2008; Heus et al., 2009; Jonker et al., 2008). This result can explain the finding that pollutants in the environment far away from cumulus clouds mix very slowly throughout the cloud layer (Verzijlbergh et al., 2009). Aircraft measurements by Wang et al. (2009) confirmed the toroidal circulation in cumulus clouds, and found that negative buoyancy is present $200 \mathrm{~m}$ outside clouds, while downdrafts prevail in the regions less than $700 \mathrm{~m}$ from cloud edges. However, a study by Wang and Geerts (2010) showed that the shell characterized by negative buoyancy is only $100 \mathrm{~m}$ for small cumulus clouds. This suggests that the characteristic lateral mixing depth somewhat scales with cloud size.

As the up-scaled counterpart of shallow convection, deep convection has been the subject of a larger number of studies (Dickerson et al., 1987; Ferek et al., 1986; Lelieveld and Crutzen, 1994) for its great efficiency in transporting pollutants from the lower boundary layer to the free atmosphere. Cotton et al. (1995) estimated that, on a global annual basis, the extratropical cyclone has the highest boundary layer mass flux of all cloud venting systems, followed by the general class of mesoscale convective systems (MCSs) excluding mesoscale convective complexes (MCCs), ordinary thunderstorms, tropical cyclones and MCCs. It has been observed that about half of the air at altitudes between 7.5 and $11.5 \mathrm{~km}$ has been influenced by convection over the past two days, and only $25 \%$ of the air has not been influenced over the past 5 days (Bertram et al., 2007). Model results of Barth et al. (2001) showed that solubility and retention of tracers in hydrometeors can alter the fate of tracers in mid-latitude convection. When soluble tracers are degassed as the parent hydrometeor is converted to ice, snow, or hail through microphysical processes, both low- and high-solubility tracers are transported to the upper troposphere; when soluble tracers are retained in ice hydrometeors, the highly soluble tracers are not ultimately transported to the troposphere but, instead, are precipitated out of the upper troposphere by snow and hail. Yin et al. (2005) found that deep convective clouds can transport aerosols from the boundary layer, detrain and then re-entrain the aerosols into the middle levels of clouds. This process contributes to a large fraction of the aerosols inside hydrometeors ( $\sim 40 \%$ by mass). Cui and Carslaw (2006) suggested a positive feedback between vertical transport efficiency of aerosol in convective clouds and increases in tropospheric aerosol abundance. Increases in aerosol concentrations reduce the precipitation efficiency and the scavenging efficiency of aerosol, and therefore allow more aerosols to be transported to the upper troposphere.

In this study, we involve an ideal passive tracer in the large eddy simulation to study the vertical transport of pollutants by shallow cumuli. Previous studies usually take advantage of observed profiles of tracer chemicals, like $\mathrm{CO}$ or $\mathrm{H}_{2} \mathrm{O}_{2}$. This can make the results close to the observations, but it is difficult to separate the influence of cumuli from other possible factors, such as chemical reactions and long-range transport. The tracer source in this study is separately prescribed at the surface and in the inversion layer, in order to analyze both the upward and downward transport mechanism by shallow cumuli and shed light on the structure of cumulus convection. The paper is organized as follows: in Sect. 2 a description of the large eddy simulation (LES) model and initialization is presented; Sect. 3 presents our results; conclusions are provided in Sect. 4.

\section{Model and case descriptions}

The large eddy simulation model used in this research is UCLA-LES, described by Stevens et al. (1999). The condensation scheme is based on the all-or-nothing assumption (bulk water parameterization): cloud water exists when relative humidity is greater than $100 \%$. We use a tracer scalar in the model to represent a certain inert insoluble pollutant, such as $\mathrm{CO}, \mathrm{O}_{3}$ and some inert aerosols. This study focuses on the transport of tracers in the dynamical field associated with non-precipitating shallow cumulus.

The simulation is set up according to the fourth intercomparison study of the Global Energy and Water Cycle Experiment (GEWEX) Cloud System Studies (GCSS) working group 1 (Siebesma et al., 2003). This intercomparison prescribed detailed initialization and parameterization of Barbados Oceanic and Meteorological Experiment (BOMEX), a typical marine shallow cumulus case. It is a non-precipitating case; thus precipitation/sedimentation process is not included in this simulation. Here we only review the model setup 


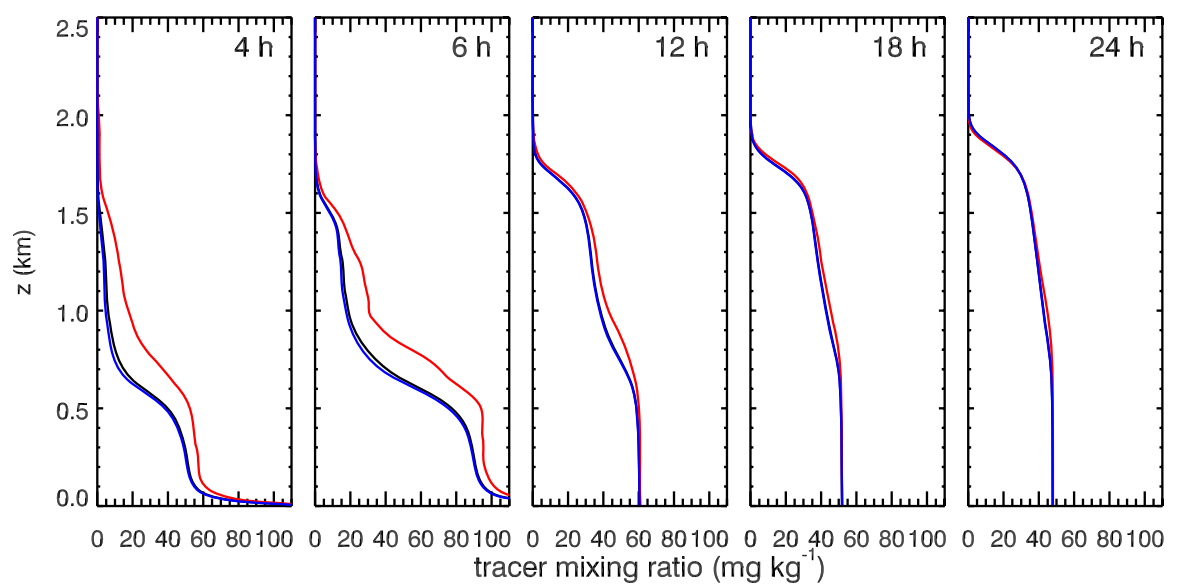

Fig. 1. Sampled profiles of tracer mixing ratio for case 1 at various moments. The black, red and blue lines represent profiles sampled over the whole domain, cloudy columns (liquid water path $>10 \mathrm{~g} \mathrm{~m}^{-2}$ ), and cloud-free columns, respectively in case 1 .

briefly. In the initial profiles, near surface is a well-mixed sub-cloud layer up to $500 \mathrm{~m}$, above which is a weakly conditionally unstable cloud layer extending to the inversion layer at about $1500 \mathrm{~m}$. The surface heat and momentum fluxes are prescribed with fixed values. Large-scale subsiding and moisture advection rates are prescribed with fixed profiles. Radiation is parameterized by prescribing a fixed radiative cooling rate; that is, no interactive radiation scheme is used in this simulation. The domain size is $6.4 \mathrm{~km} \times 6.4 \mathrm{~km} \times 3 \mathrm{~km}$, with doubly periodic lateral boundary. The resolution is $\Delta x=\Delta y=25 \mathrm{~m}$ and $\Delta z=10 \mathrm{~m}$. This resolution can relatively well resolve the cloud structure, hence is suitable for studying the effects of shallow cumulus clouds in vertical transport process of pollutants. The simulation is run for $24 \mathrm{~h}$ and data are recorded every $5 \mathrm{~min}$. The idealized setup based on BOMEX has the practical advantage of a lack of a diurnal cycle. This makes longer runs possible and ensures a statistically identical cloud field over the entire run. The Smagorinsky model is chosen as the SGS-TKE model, in which TKE is diagnostic, not prognostic, so no initialization for TKE is made as that in Siebesma et al. (2003).

Two cases are run in this study. In case 1, the tracer source is uniformly distributed at the surface to investigate vertical transport of pollutants from the surface. The source releases tracers into the domain with a constant mass flux of $5.78 \mathrm{mg} \mathrm{m}^{-2} \mathrm{~s}^{-1}$ from $2 \mathrm{~h}$ to $6 \mathrm{~h}$ (here and after, all time refers to model simulation time). In case 2 , a tracer is instantly released into the domain at $z=1.6 \sim 2.0 \mathrm{~km}$ with a uniform mixing ratio of $100 \mathrm{mg} \mathrm{kg}^{-1}$ at $2 \mathrm{~h}$. Tracers at this height can be considered to be pollutants transported there over a long range by synoptic systems. The tracer source strength and initial concentration can be linearly scaled to any passive pollutants.

\section{Results}

\subsection{Case 1: vertical transport of pollutants from the surface}

Figure 1 presents profiles of tracer mixing ratio averaged over the whole domain, cloudy columns (liquid water path LWP $>10 \mathrm{~g} \mathrm{~m}^{-2}$ ), and cloud-free columns at different moments. The constant source of tracer at the surface is on from $2 \mathrm{~h}$ to $6 \mathrm{~h}$, and there is no source from $6 \mathrm{~h}$ to $24 \mathrm{~h}$. Tracers released from the surface are gradually transported to the cloud layer and even into the inversion layer. Higher tracer mixing ratio can be seen in the cloudy columns. Note that tracer mixing ratio averaged over the whole domain is almost the same as that over the cloud-free columns, due to the small cloud fraction $(8.4 \%$ averaged over the last $22 \mathrm{~h})$ in this simulation.

When the source is on (e.g., $4 \mathrm{~h}$ and $6 \mathrm{~h}$ ), a notable feature is that significant gradients of tracer mixing ratio are maintained near the surface and around cloud base. Tracer mixing ratio over cloudy columns is significantly higher than that over cloud-free columns, not only in the cloud layer (about $0.7-1.5 \mathrm{~km}$ ) but also in the sub-cloud layer (about $0-0.7 \mathrm{~km}$ ) and the inversion layer (about $1.5-2 \mathrm{~km}$ ). This suggests that pollutants are brought below clouds from nearby regions by convergent flows below clouds, increasing local pollution but decreasing nearby pollution, and then efficiently transport pollutants from the sub-cloud layer into the cloud layer. Some higher clouds manage to get into the inversion layer and bring pollutants there.

After the source is shut down ( $12 \mathrm{~h}, 18 \mathrm{~h}$ and $24 \mathrm{~h})$, tracers continue to be transported upward and vertical gradients near the surface are neglectable, while gradients around cloud base are still significant. Tracer mixing ratio becomes higher in cloud and inversion layers but lower in the sub-cloud layer. This indicates that tracers become well-mixed vertically in 

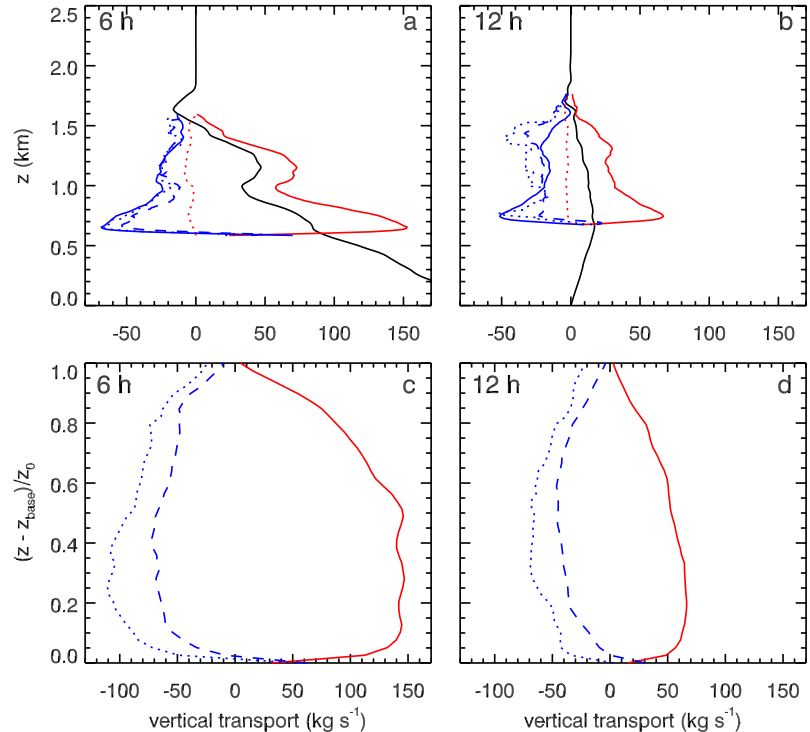

Fig. 2. Sampled profiles of tracer vertical transport at $6 \mathrm{~h}$ and $12 \mathrm{~h}$ from case 1 . To better illustrate the effect of clouds on the vertical transport, we concentrated on cloudy grids (liquid water mixing ratio $>0.01 \mathrm{~g} \mathrm{~kg}^{-1}$ ) and cloud-free grids here. The black, red, and blue solid lines represent profiles over the whole domain, cloudy grids, and cloud-free grids, respectively. The blue-dotted and bluedashed lines represent profiles sampled over cloud-free grids within $600 \mathrm{~m}$ from cloud edges and cloud-free grids within $200 \mathrm{~m}$ from cloud edges. The red-dotted lines represent profiles sampled over cloudy grids with negative vertical velocity. The downward transport in cloudy regions is much weaker than the upward transport in cloudy regions and the downward transport in cloud-free regions, as will be discussed in more detail in Fig. 7. In (a) and (b), profiles are plotted with respect to height. In (c) and (d), transport related to each cloud is non-dimensionalized with respect to the depth $\left(z_{0}\right)$ of that cloud. Note that clouds with cloud base higher than $1400 \mathrm{~m}$ are not included in the non-dimensionalized profiles.

the boundary layer. It is seen that, during this time period, cloudy columns still have higher tracer mixing ratio than cloud-free columns, but the difference becomes smaller with time, suggesting that tracers become mixed better horizontally. For example, at $12 \mathrm{~h}$, tracer mixing ratio is significantly higher in the cloudy columns than in cloud-free columns in cloud and inversion layers $(0.6-2.0 \mathrm{~km})$, but shows no difference in the sub-cloud layer (below $0.6 \mathrm{~km}$ ). Cloudy-columns and cloud-free columns show smaller difference in the cloud layer $(0.6-1.5 \mathrm{~km})$ at $18 \mathrm{~h}$, and even smaller at $24 \mathrm{~h}$.

Figure 2 presents profiles of the vertical transport of tracers at $6 \mathrm{~h}$ and $12 \mathrm{~h}$ (panels a and b). These two moments are selected to represent the transport features with and without the surface source. Similar to Fig. 1, we investigate the vertical transport over three regimes: (1) the whole domain; (2) the cloudy grids (liquid water mixing ratio $>0.01 \mathrm{~g} \mathrm{~kg}^{-1}$ ); (3) the cloud-free grids. We choose these regimes, especially cloudy grids, to show the important effect of cumulus trans- port. The vertical transport at each grid is defined as the mass of tracers vertically transported in unit time (Flossmann and Wobrock, 1996), $(\rho w r+\operatorname{sgf}) A$, where $\rho$ is the air density, $w$ is the vertical component of air velocity, $r$ is the tracer mixing ratio, $\rho w r$ is the resolvable scale flux, sgf is the sub-grid scale flux, and $A$ is the horizontal cross section of the grid. The total transport over the domain is upward throughout the boundary layer for both $6 \mathrm{~h}$ and $12 \mathrm{~h}$. Sub-grid scale transport dominates the resolvable scale transport near the surface, but is much smaller than the resolvable scale transport in the cloud layer and above (figure not shown there). The total transport becomes weaker at $12 \mathrm{~h}$, because the tracer is better mixed in the boundary layer (see $12 \mathrm{~h}$ in Fig. 1). It is seen that cloudy grids contribute to upward transport, while cloud-free grids contribute to downward transport in the cloud layer for both $6 \mathrm{~h}$ and $12 \mathrm{~h}$. Because the cloud coverage is only $8.4 \%$, it can be inferred that the upward transport per cloudy grid is much stronger than the downward transport per cloud-free grid.

It is seen from above that upward transport is associated with cloudy grids and downward transport is associated with cloud-free grids. Recent studies showed that, in the cloudfree regions, cumulus clouds can induce downdrafts that prevail in thin shells close to cloud edges (e.g., Wang et al., 2009). This suggests that the downward transport in cloudfree grids may also be affected by clouds. Figure $2 \mathrm{a}$ and $\mathrm{b}$ show how much downward transport is associated with cumulus clouds. For each cloud-free grid in the cloud layer, we specify its distance to cloud as its horizontal distance to the nearest cloud edge, similar to what Jonker et al. (2008) did. Cloud-free grids within $200 \mathrm{~m}$ from cloud edges take up about $20 \%$ of the domain area, and cloud-free grids within $600 \mathrm{~m}$ from cloud edges take up about $60 \%$ (figure not shown). However, results show that cloud-free grids within $600 \mathrm{~m}$ from cloud edges contribute almost all the downward transport. Moreover, grids within $200 \mathrm{~m}$ from cloud edges contribute a large fraction of the total downward transport, in spite of the relative small coverage. This indicates that the downward transport outside clouds prevail within about $600 \mathrm{~m}$ from cloud edges, consistent with the aircraft measurements of downdrafts around cumulus clouds by Wang et al. (2009). This also indicates that tracers detrained from clouds tend to be distributed in the thin shells within $200 \mathrm{~m}$ around clouds. The results are even clearer when data are non-dimensionalized. In panels $\mathrm{c}$ and $\mathrm{d}$ of Fig. 2, transport over cloudy grids is non-dimensionalized with the depth of that cloud, while transport over cloud-free grids is nondimensionalized using the depth of the nearest cloud to it. It is seen that cloudy grids contribute to the upward transport, while cloud-free grids contribute to the downward transport. Downward transport over cloud-free grids within $200 \mathrm{~m}$ is much stronger than that over cloud-free grids further away from clouds. This indicates that the downward transport is also induced by the cumulus clouds. 

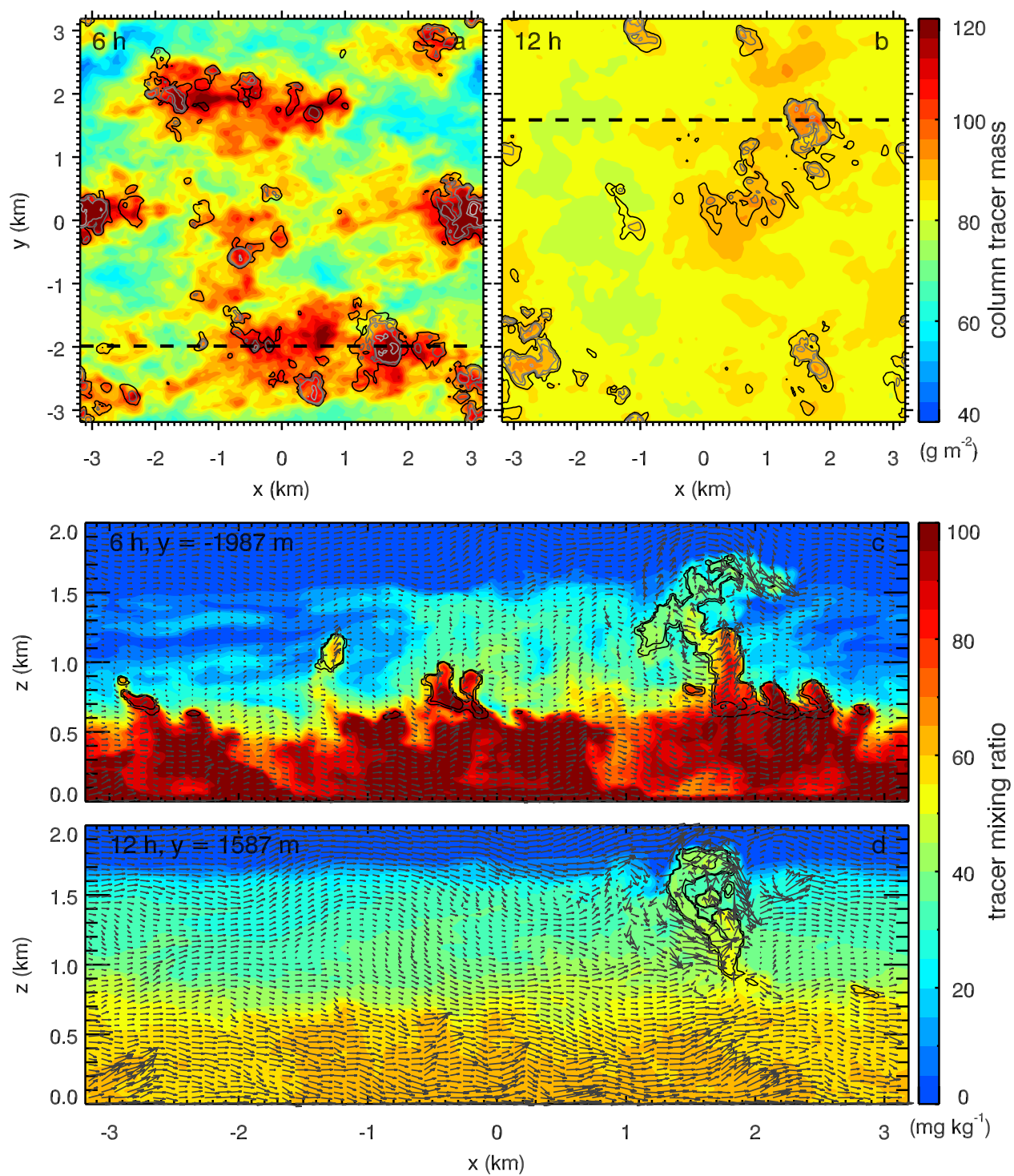

Fig. 3. Snapshots of column integral tracer mass (a, b) and two selected vertical cross sections (c, d). In (a) and (b), the contours from dark to light indicate liquid water path with increasing values of $10,50,100,300$ and $500 \mathrm{~g} \mathrm{~m}^{-2}$. It is shown that cloudy columns usually have higher tracer mixing ratio than cloud-free columns. In (c) and (d), the contours indicate liquid water mixing ratio with increasing values of $0.01,0.1$ and $1 \mathrm{~g} \mathrm{~kg}^{-1}$, and the arrows indicate $\mathrm{u}-\mathrm{w}$ wind components.

Figure 3 presents the snapshots of column-integrated tracer mass at $6 \mathrm{~h}$ and $12 \mathrm{~h}$, accompanied by vertical cross sections at these two moments. Figure $3 \mathrm{a}$ and $\mathrm{b}$ show that column-integrated tracer mass in cloudy columns is higher than that in cloud-free columns, consistent with results in Fig. 1. The higher tracer mass in cloud-free columns (e.g., $x=-1.0-1.0 \mathrm{~km}, y=-2.5$ to $-1.5 \mathrm{~km}$ at $6 \mathrm{~h}$, also shown in the vertical cross section of panel c) is attributed to evaporated clouds that were previously in these regions. Cumulus clouds in the case simulated in this study have a lifetime of about $20-30 \mathrm{~min}$, as can be seen in Jiang et al. (2006). At any moment, clouds in the domain can be at different stages: forming, developing, and decaying; cloud-free regions in the domain may also be cloudy in previous moments. Tracers of high mixing ratio in cloud-free regions will gradually become diluted by the cloud-free boundary layer turbulence, which can be clearly seen in snapshots after $6 \mathrm{~h}$ (figures not shown here). In the vertical cross sections in Fig. 3c and $\mathrm{d}$, it is seen that pollutants are transported out of the lower boundary through cloudy regions. Higher mixing ratios of pollutants are found in cloudy columns than in the cloud-free columns, both in the cloud layer and in the sub-cloud layer (e.g., clouds at $x=1.0-3.0 \mathrm{~km}$ at both $6 \mathrm{~h}$ and $12 \mathrm{~h}$ ), which confirms the results from Fig. 1. Some clouds penetrate into 


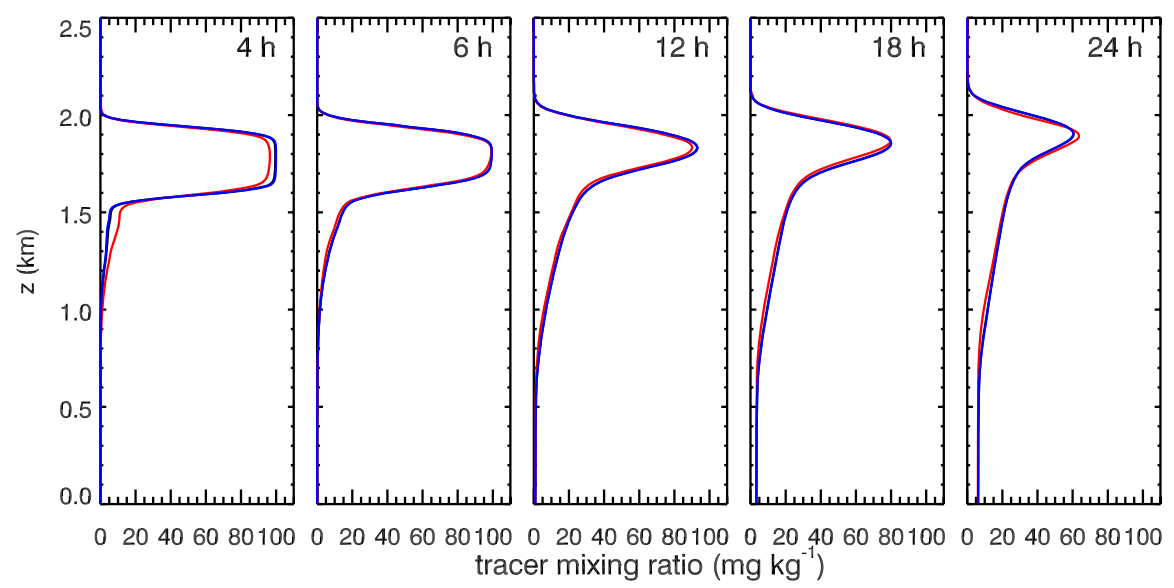

Fig. 4. As in Fig. 1, but for case 2, where tracers are released into the inversion layer at $2 \mathrm{~h}$. The cumulus convection is able to transport tracers from the inversion layer downward into the cloud and sub-cloud layers.
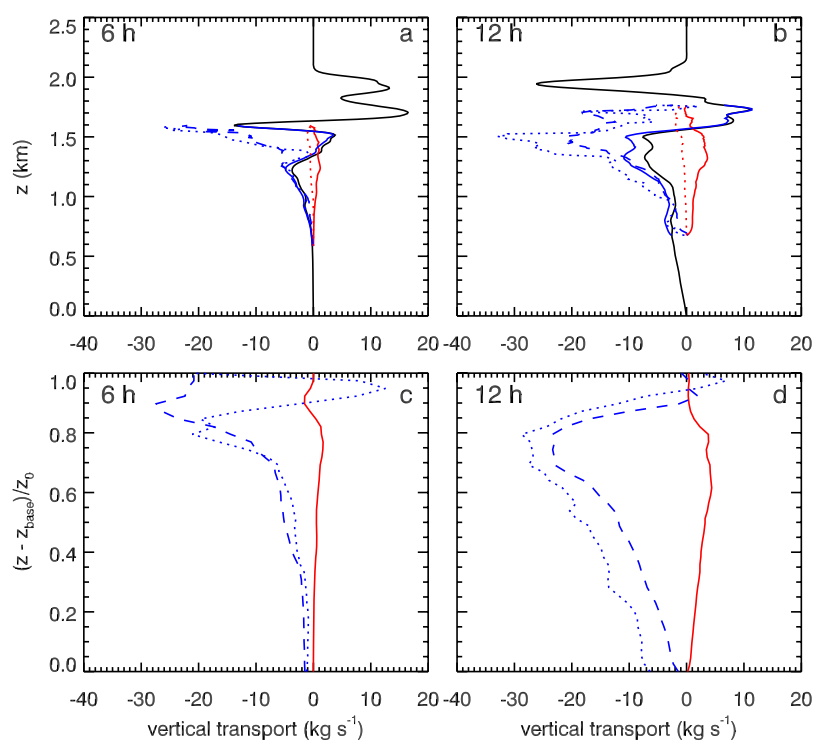

Fig. 5. As in Fig. 2, but for case 2, where tracers are released into the initial inversion layer at $2 \mathrm{~h}$.

the inversion layer and transport pollutants directly to the inversion layer (e.g., clouds at $x=1.0-3.0 \mathrm{~km}$ at both $6 \mathrm{~h}$ and $12 \mathrm{~h})$.

\subsection{Case 2: vertical transport of pollutants from the inversion layer}

In case 2, a tracer with uniform mixing ratio is released at $2 \mathrm{~h}$ at $z=1.6-2.0 \mathrm{~km}$ (i.e., the inversion layer). Figure 4 presents profiles of tracer mixing ratio averaged over the whole domain, cloudy columns (liquid water path $\mathrm{LWP}>10 \mathrm{~g} \mathrm{~m}^{-2}$ ), and cloud-free columns at different moments in case 2 . Tracers in the inversion layer are gradually transported down to the layers below. Tracer mixing ratio becomes lower in the inversion layer and higher in the lower boundary layer. At $4 \mathrm{~h}, 6 \mathrm{~h}$ and $12 \mathrm{~h}$, tracers are mixed into the cloud layer, and there are nearly no tracers in the sub-cloud layer. At $18 \mathrm{~h}$ and $24 \mathrm{~h}$, tracers are shown to become mixed into the sub-cloud layer, which has higher tracer mixing ratio with time. It is seen that, in the cloud layer, tracer mixing ratio in cloudy columns is usually a little smaller than that in cloud-free columns. This indicates that cumulus clouds pump relatively clean air upward from the sub-cloud layer.

Figure 5 shows profiles of vertical transport over different regimes at $6 \mathrm{~h}$ and $12 \mathrm{~h}$ for case 2 . In the inversion layer, great values of vertical transport at both $6 \mathrm{~h}$ and $12 \mathrm{~h}$ are induced by oscillating movement of air and high tracer mixing ratio. When averaged over time, the vertical transport in the inversion layer is not as significant as in Fig. 5. Below the inversion layer, the total transport in the domain is negative (downward) at both $6 \mathrm{~h}$ and $12 \mathrm{~h}$. Similar to case 1 , cloudy grids contribute to upward transport, while cloud-free grids contribute to downward transport, and the downward transport is found to mainly occur in the thin regions around clouds. This can also be seen in the non-dimensionalized transport in panels $\mathrm{c}$ and $\mathrm{d}$. Another interesting feature is that, despite the lack of tracers in the sub-cloud layer at $6 \mathrm{~h}$ and $12 \mathrm{~h}$, cloudy grids already have a significant upward transport. This indicates that tracers are laterally mixed into clouds through the lower part of the cloud layer. This is consistent with the results of Zhao and Austin (2005b), which confirm toroidal circulations associated with cumulus clouds. With such circulations, tracers are entrained into clouds through the lower part of the clouds and detrained through the upper part. Therefore the shallow cumulus clouds have net convergence in the lower part and net divergence in the upper part, as presented in Chen et al. (2012).

Figure 6 presents the snapshots of column-integral tracer mass at $6 \mathrm{~h}$ and $12 \mathrm{~h}$. Cloudy regions usually have lower 

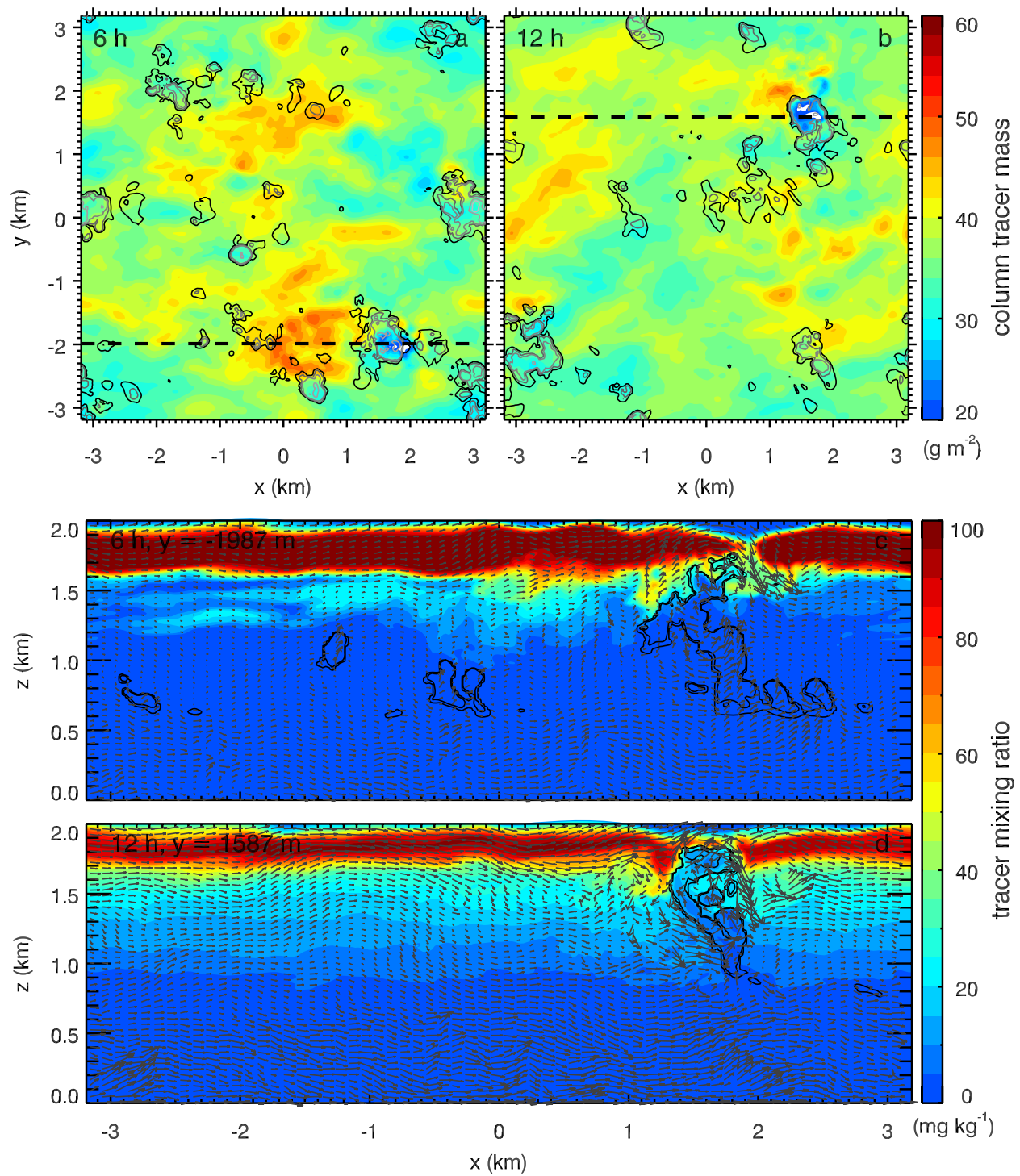

Fig. 6. As in Fig. 3, but for case 2. In (a) and (b), cloud columns usually have lower tracer mixing ratio. Panels (c) and (d) confirm this, and show that cloud-free grids are responsible for downward transport, which mainly occurs in thin regions around clouds, indicating that the downward transport is also induced by cumulus clouds.

tracer mass, consistent with Fig. 4. Some exceptions are shown, for example, in the region $x=-1.0-0.0 \mathrm{~km}$ and $y=-2.0$ to $-1.5 \mathrm{~km}$; tracer concentration in the cloud is almost the same with surrounding regions. This is attributed to the cloud's low top, and it is clearly shown in the vertical cross section (Fig. 6c). In the vertical cross sections, it is seen that cumulus clouds work as bubbles bringing clean air from the sub-cloud layer into the cloud layer, thus diluting pollution there. Polluted air is forced downward around the cloud edges (e.g., clouds at $x=1.0-3.0 \mathrm{~km}$ at both $6 \mathrm{~h}$ and $12 \mathrm{~h}$ ). In the regions with high clouds that grow into the pollutant layer, significant downward transport of polluted air is found just around the cloud edges, while upward transport of clean air is found in clouds. But in regions without clouds and regions where clouds cannot get into the pollutant layer, pollutants display oscillating behaviors, and neglectable downward transport is shown. This is consistent with the results of Verzijlbergh et al. (2009), where pollutants far away from the cumulus can be hardly affected by cumulus circulations.

Because downdrafts may also exist in cloudy regions, Fig. 7 presents the distribution of vertical velocity in cloudy grids. It shows that downdrafts occur in clouds, but are much weaker and less frequent than updrafts. Recall that, in Figs. 2 and 5, the downward transport in cloudy regions is much weaker than the upward transport in cloudy regions and the downward transport in cloud-free regions. This confirms the 

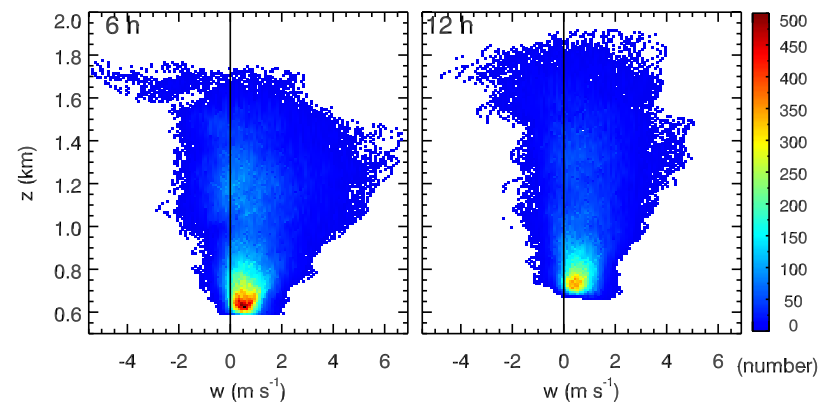

Fig. 7. Distribution of vertical velocity in cloudy grids. The bin width is $0.1 \mathrm{~m} \mathrm{~s}^{-1}$. The black lines indicate the zero vertical velocity. Downdrafts occur in clouds, but are much weaker and less frequent than updrafts.

findings in case 1 and case 2 that upward transport dominates cloudy regions. It also shows that many cloudy grids exist in the inversion layer at $6 \mathrm{~h}$ and $12 \mathrm{~h}$ (the inversion layer height is about $1.56 \mathrm{~km}$ at $6 \mathrm{~h}$ and $1.65 \mathrm{~km}$ at $12 \mathrm{~h}$ ). This means that some active cumuli can penetrate into the inversion layer, transporting pollutants from the surface upward into the inversion layer, and also transporting pollutants from the inversion layer downward to the lower layer.

\section{Conclusions}

A passive tracer is used in large eddy simulations for studying the vertical transport of pollutants by shallow cumuli. The tracer source is continuous for $4 \mathrm{~h}$ at the surface in one case, and is instant in the inversion layer in the other case to investigate both the upward and downward transport associated with cumulus clouds. Results show that shallow cumuli are able to both vent pollutants from the surface upward to the cloud layer and fumigate pollutants from the inversion layer downward into the lower boundary layer. When the tracer source is at the surface, it is found that cloudy regions are responsible for the upward transport due to intense updrafts in cloudy regions. When the tracer source is in the inversion layer, it is found that cloud-free regions, mainly the thin shells about $600 \mathrm{~m}$ from cloud edges, are responsible for the downward transport. This is consistent with aircraft measurements of downdrafts around cumulus clouds by Wang et al. (2009), and indicates that the downward transport is also induced by cumulus clouds.

However, because shallow cumulus clouds can hardly grow to the free atmosphere, cumuli in this study do not show ability to accomplish the across-inversion transport. This confirms previous results that the across-inversion transport is mostly dominated by the more vigorous convective clouds.
Acknowledgements. We thank Jost Heintzenberg for helpful discussions and suggestions on this manuscript. We are also grateful to the anonymous reviewer and Thijs Heus for their comments and suggestions, which improved this manuscript. This work is supported by Chinese NSF grant 41075097 and Chinese National Public Benefit Research Foundation of Meteorology Grant GYHY201006011.

Edited by: C. Hoose

\section{References}

Barth, M. C., Stuart, A. L., and Skamarock, W. C.: Numerical simulations of the July 10, 1996, Stratospheric-Tropospheric Experiment: Radiation, Aerosols, and Ozone (STERAO)-Deep Convection experiment storm: Redistribution of soluble tracers, J. Geophys. Res.-Atmos., 106, 12381-12400, 2001.

Bertram, T. H., Perring, A. E., Wooldridge, P. J., Crounse, J. D., Kwan, A. J., Wennberg, P. O., Scheuer, E., Dibb, J., Avery, M., Sachse, G., Vay, S. A., Crawford, J. H., McNaughton, C. S., Clarke, A., Pickering, K. E., Fuelberg, H., Huey, G., Blake, D. R., Singh, H. B., Hall, S. R., Shetter, R. E., Fried, A., Heikes, B. G., and Cohen, R. C.: Direct measurements of the convective recycling of the upper troposphere, Science, 315, 816-820, 2007.

Chen, G., Xue, H., Zhang, W., and Zhou, X.: The threedimensional structure of precipitating shallow cumuli. Part one: The kinematics, Atmos. Res., 112, 70-78, doi:10.1016/j.atmosres.2012.04.007, 2012.

Ching, J. K. S. and Alkezweeny, A. J.: Tracer study of vertical exchange by cumulus clouds, J. Clim. Appl. Meteorol., 25, 1702$1711,1986$.

Cotton, W. R., Alexander, G. D., Hertenstein, R., Walko, R. L., McAnelly, R. L., and Nicholls, M.: Cloud venting - A review and some new global annual estimates, Earth-Sci. Rev., 39, 169-206, 1995.

Cui, Z. Q. and Carslaw, K. S.: Enhanced vertical transport efficiency of aerosol in convective clouds due to increases in tropospheric aerosol abundance, J. Geophys. Res.-Atmos., 111, D15212, doi:10.1029/2005JD006781, 2006.

Dickerson, R. R., Huffman, G. J., Luke, W. T., Nunnermacker, L. J., Pickering, K. E., Leslie, A. C. D., Lindsey, C. G., Slinn, W. G. N., Kelly, T. J., Daum, P. H., Delany, A. C., Greenberg, J. P., Zimmerman, P. R., Boatman, J. F., Ray, J. D., and Stedman, D. H.: Thunderstorms: An important mechanism in the transport of air pollutants, Science, 235, 460-464, 1987.

Edy, J., Cautenet, S., and Bremaud, P.: Modeling ozone and carbon monoxide redistribution by shallow convection over the Amazonian rain forest, J. Geophys. Res.-Atmos., 101, 28671-28681, 1996.

Ferek, R. J., Chatfield, R. B., and Andreae, M. O.: Vertical distribution of dimethylsulfide in the marine atmosphere, Nature, 320, 514-516, 1986.

Flossmann, A. I.: Clouds and pollution, Pure Appl Chem, 70, 13451352, 1998.

Flossmann, A. I. and Wobrock, W.: Venting of gases by convective clouds, J. Geophys. Res.-Atmos., 101, 18639-18649, 1996.

Heus, T. and Jonker, H. J. J.: Subsiding shells around shallow cumulus clouds, J. Atmos. Sci., 65, 1003-1018, doi:10.1175/2007jas2322.1, 2008. 
Heus, T., Pols, C. F. J., Jonker, H. J. J., Van den Akker, H. E. A., and Lenschow, D. H.: Observational validation of the compensating mass flux through the shell around cumulus clouds, Q. J. Roy. Meteor. Soc., 135, 101-112, doi:10.1002/Qj.358, 2009.

Jiang, H. L., Xue, H. W., Teller, A., Feingold, G., and Levin, Z.: Aerosol effects on the lifetime of shallow cumulus, Geophys. Res. Lett., 33, L14806, doi:10.1029/2006g1026024, 2006.

Jonker, H. J. J., Heus, T., and Sullivan, P. P.: A refined view of vertical mass transport by cumulus convection, Geophys. Res. Lett., 35, L07810, doi:10.1029/2007g1032606, 2008.

Lelieveld, J. and Crutzen, P. J.: Role of deep cloud convection in the ozone budget of the troposphere, Science, 264, 1759-1761, 1994.

Niewiadomski, M.: A passive pollutant in a three-dimensional field of convective clouds: Numerical simulations, Atmos. Environ., 20, 139-145, 1986.

Siebesma, A. P., Bretherton, C. S., Brown, A., Chlond, A., Cuxart, J., Duynkerke, P. G., Jiang, H. L., Khairoutdinov, M., Lewellen, D., Moeng, C. H., Sanchez, E., Stevens, B., and Stevens, D. E.: A large eddy simulation intercomparison study of shallow cumulus convection, J. Atmos. Sci., 60, 1201-1219, 2003.

Stevens, B., Moeng, C. H., and Sullivan, P. P.: Large-eddy simulations of radiatively driven convection: Sensitivities to the representation of small scales, J. Atmos. Sci., 56, 3963-3984, 1999.

Thompson, A. M., Pickering, K. E., Dickerson, R. R., Ellis, W. G., Jacob, D. J., Scala, J. R., Tao, W. K., Mcnamara, D. P., and Simpson, J.: Convective transport over the central United-States and its role in regional $\mathrm{CO}$ and ozone budgets, J. Geophys. Res.Atmos., 99, 18703-18711, 1994.

Vilà-Guerau de Arellano, J., Kim, S.-W., Barth, M. C., and Patton, E. G.: Transport and chemical transformations influenced by shallow cumulus over land, Atmos. Chem. Phys., 5, 3219-3231, doi:10.5194/acp-5-3219-2005, 2005.
Verzijlbergh, R. A., Jonker, H. J. J., Heus, T., and Vilà-Guerau de Arellano, J.: Turbulent dispersion in cloud-topped boundary layers, Atmos. Chem. Phys., 9, 1289-1302, doi:10.5194/acp-91289-2009, 2009.

Wang, Y. G. and Geerts, B.: Humidity variations across the edge of trade wind cumuli: Observations and dynamical implications, Atmos. Res., 97, 144-156, doi:10.1016/j.atmosres.2010.03.017, 2010.

Wang, Y. G., Geerts, B., and French, J.: Dynamics of the cumulus cloud margin: An observational study, J. Atmos. Sci., 66, 36603677, 2009.

Warren, S. G., Hahn, C. J., London, J., Chervine, R. M., and Jenne, R. L.: Global distribution of total cloud cover and cloud type amounts over land, NCAR Tech. Note NCAR/TN-273+STR, 29, 1986.

Warren, S. G., Hahn, C. J., London, J., Chervine, R. M., and Jenne, R. L.: Global distribution of total cloud cover and cloud type amounts over ocean, NCAR Tech. Note NCAR/TN-317+STR 42, 1988.

Yin, Y., Carslaw, K. S., and Feingold, G.: Vertical transport and processing of aerosols in a mixed-phase convective cloud and the feedback on cloud development, Q. J. Roy. Meteor. Soc., 131, 221-245, 2005.

Zhao, M. and Austin, P. H.: Life cycle of numerically simulated shallow cumulus clouds. Part I: Transport, J. Atmos. Sci., 62, 1269-1290, 2005a.

Zhao, M. and Austin, P. H.: Life cycle of numerically simulated shallow cumulus clouds. Part II: Mixing dynamics, J. Atmos. Sci., 62, 1291-1310, 2005b. 